\title{
openheart Hospital admissions for stroke and bleeding in Hounslow following a quality improvement initiative
}

\author{
Kam Ying Wong, ${ }^{1}$ Bethan Davies (D) , ${ }^{2}$ Yewande Adeleke (D) , ${ }^{1}$ Thomas Woodcock, ${ }^{1}$ \\ Dionne Matthew, ${ }^{3}$ Sara Sekelj, ${ }^{4}$ Andi Orlowski, ${ }^{1,4}$ Bradley Porter, ${ }^{5,6}$ \\ Sophia Hashmy, ${ }^{7}$ Ammu Mathew, ${ }^{2}$ Ron Grant, ${ }^{8}$ Agnes Kaba, ${ }^{2}$ \\ Brigitte Unger-Graeber, ${ }^{9}$ Bruno Petrungaro, ${ }^{4}$ Jordan Wallace, ${ }^{10}$ Derek Bell, ${ }^{1}$ \\ Martin R Cowie, ${ }^{11}$ Sadia Khan (i) ${ }^{2}$
}

To cite: Wong KY, Davies B, Adeleke Y, et al. Hospital admissions for stroke and bleeding in Hounslow following a quality improvement initiative. Open Heart 2021;8:e001558. doi:10.1136/ openhrt-2020-001558

Received 1 January 2021 Revised 31 January 2021 Accepted 1 February 202
Check for updates

(C) Author(s) (or their employer(s)) 2021. Re-use permitted under CC BY-NC. No commercial re-use. See rights and permissions. Published by BMJ.

For numbered affiliations see end of article.

Correspondence to Dr Sadia Khan; sadiakhan1@ nhs.net

\section{ABSTRACT}

Objective Atrial fibrillation (AF) is the most common arrhythmia. Undiagnosed and poorly managed AF increases risk of stroke. The Hounslow AF quality improvement (QI) initiative was associated with improved quality of care for patients with AF through increased detection of $\mathrm{AF}$ and appropriate anticoagulation. This study aimed to evaluate whether there has been a change in stroke and bleeding rates in the Hounslow population following the QI initiative.

Methods Using hospital admissions data from January 2011 to August 2018, interrupted time series analysis was performed to investigate the changes in standardised rates of admission with stroke and bleeding, following the start of the Ql initiative in October 2014

Results There was a $17 \%$ decrease in the rate of admission with stroke as primary diagnosis (incidence rate ratio (IRR) $0.83 ; 95 \% \mathrm{Cl} 0.712$ to $0.963 ; p<0.014$ ). There was an even larger yet not statistically significant decrease in admission with stroke as primary diagnosis and $\mathrm{AF}$ as secondary diagnosis (IRR $0.75 ; 95 \% \mathrm{Cl} 0.550$ to $1.025 ; p<0.071)$. No significant changes were observed in bleeding admissions. For each outcome, an additional regression model including both the level change and an interaction term for slope change was created. In all cases, the slope change was small and not statistically significant.

Conclusion Reduction in stroke admissions may be associated with the AF QI initiative. However, the immediate level change and non-significant slope change suggests a lack of effect of the intervention over time and that the decrease observed may be attributable to other events.

\section{INTRODUCTION}

The most common cardiac arrhythmia, ${ }^{1}$ atrial fibrillation $(\mathrm{AF})$ is associated with a fivefold increase in the risk of ischaemic stroke and older populations are particularly vulnerable. ${ }^{2}$ In the UK, it is estimated that over 7000 AF-related strokes per year could be prevented with oral anticoagulation (OAC). ${ }^{3}$

\section{Key questions}

What is already known about this subject?

- Atrial fibrillation (AF) is a common cardiac arrhythmia and increases the risk of ischaemic stroke. Evidence has shown that opportunistic screening using technological devices is a cost-effective measure for early detection of silent or subclinical symptomatic AF. Subsequent risk stratification and oral anticoagulation after diagnosis of $\mathrm{AF}$ can vastly reduce AF-related stroke.

What does this study add?

- With early diagnosis of AF and oral anticoagulation optimisation followed by the implementation of quality improvement (QI) initiative in primary care, stroke admission to secondary care may be reduced without a significant increase in bleeding admissions.

How might this impact on clinical practice?

- In regions where undiagnosed or poorly managed AF is evident, similar QI effort may prove beneficial in reducing the burden of stroke on both patients with $\mathrm{AF}$ and the healthcare system.

The Borough of Hounslow in London had a population of $294712^{4}$ in 2014. The observed AF prevalence in Hounslow was $0.9 \%$ in contrast to an expected prevalence of $1.6 \%$, suggesting there were around 2000 residents with undiagnosed $\mathrm{AF}^{5}$ The admission rate for stroke in Hounslow (191 per $100000)$ was higher than the national rate for England (171.9 per 100 000). Furthermore, only $56.7 \%$ of patients who had stroke admitted to hospital with pre-existing AF were taking anticoagulation. ${ }^{6}$ The Sentinel Stroke National Audit Programme in 2014 showed that for patients with AF in Hounslow not anticoagulated before stroke, after discharge there was $47 \%$ mortality and $20 \%$ severe morbidity. ${ }^{7}$ 
Opportunistic screening has been identified as a costeffective solution for detecting the population with silent or subclinical symptomatic AF. ${ }^{8}$ With technological advancement, many screening methods can be adopted in addition to the traditional pulse palpation and 12-lead ECG. ${ }^{9}{ }^{10}$ AF-related stroke risk can be vastly reduced by early diagnosis of $\mathrm{AF}$, risk stratification and preventive OAC. ${ }^{112}$ However, common complications of OAC such as gastrointestinal bleeding and intracranial haemorrhage, ${ }^{11}$ also have significant societal costs. ${ }^{13}$

In 2014, an initiative was set up to improve AF detection and management in all Hounslow general practices (GP), aiming to translate evidence-based interventions into routine practice using quality improvement (QI) methodologies. ${ }^{14}$ This resulted in an increase in the rate of new AF diagnoses and an increase in anticoagulation prescription. ${ }^{15}$ This study aims to evaluate whether consequently there has been a change in stroke and bleeding rates in the Hounslow population following the initiative.

\section{METHODS}

\section{Hounslow QI initiative}

The QI initiative comprised of education and specialist support for general practitioners (GP on diagnosis and management of AF). This included a KardiaMobile (AliveCor, Mountain View, California, USA) handheld ECG device demonstration and distribution to all GP for opportunistic AF screening, creation of an AF 'at-risk' register and patient status alert, a SystmOne AF clinical template to help improve compliance with NICE guidance and patient-centred anticoagulation choices, cardiology nurse review of exception-reported patients and patients on aspirin, nurse-led face-to-face anticoagulation clinics and patient education about AF. Details of the multidisciplinary QI team, the interventions and processrelated measures have previously been described. ${ }^{15}$

\section{Patient and public involvement}

Patients were involved in the design and conduct of the AF QI initiative through to the authorship of this paper. Development of the shared aim, measures for improvement and iterative testing of the changes was informed by discussions with a patient representative within the multidisciplinary QI team, who had experience of AF. Patients were central to dissemination of information about $\mathrm{AF}$ diagnosis and its management, which helped to increase community awareness during and beyond the AF initiative. We intend to disseminate the main results to the public and will seek patient and public involvement for development of an appropriate dissemination strategy.

\section{Data source and extraction}

Clinical Commissioning Groups (CCGs) commission the majority of health services for their responsible areas for which they are responsible. Aggregated data on hospital admissions for patients registered with GPs from Hounslow CCG during January 2010 and December 2018 were extracted. The data were taken from the National Health
Service (NHS) Hospital Episode Statistics (HES) database containing details of clinical admission and emergency attendance at NHS hospitals in England. ${ }^{16}$ Diagnoses were defined in the database according to the codes of the WHO International Classification of Diseases-10th revision (ICD-10). ${ }^{17}$ The following codes were used in the analyses: (1) AF (I48X); (2) stroke (I61.0 to I61.6, I61.8 to I61.9; I63.0 to I63.6, I63.8 to I63.9; I64X); (3) bleeding (K92.0 to K92.2; R31; R58) and (4) use of OAC (Z92.1).

The total population registered with GPs in Hounslow, stratified by month and year, was derived by retrospective extraction of pseudonymised data from Hounslow CCG's SystmOne clinical GP database. Data were extracted for the period starting January 2011 to August 2018 for the following events: registration with a GP practice and deduction from practice list. Deduction refers to removal from practice list due to death or deregistration for example, patients registering with a new GP outside of Hounslow borough. These data elements were extracted alongside age and gender of the patient. Data validation was conducted by a senior GP, who compared a sample of extracted data with patient clinical records.

\section{Measures}

The primary outcome of our investigation was the rate of hospital admissions for stroke, specifically the monthly rate of (1) admission with stroke as primary diagnosis and (2) 6-monthly rate of admission with stroke as primary diagnosis and $\mathrm{AF}$ as secondary diagnosis.

To understand whether efforts to increase prescription of OAC in patients with an AF diagnosis had inadvertently increased bleeding admissions, we measured the 6-monthly rate of (1) admission with bleeding as primary diagnosis and $\mathrm{AF}$ in any position of diagnosis and (2) admission with bleeding as primary diagnosis and the use of OAC as secondary diagnosis.

\section{Statistical analysis}

Descriptive statistics are presented as numbers (percentages) or mean (SD) for categorical and continuous variables, respectively. For each year from 2011 to 2018, we analysed the (1) average monthly expected AF prevalent population; and for each of the four measures, the average monthly: (2) incidence; (3) incidence stratified by sex; (4) incidence stratified by three age-groups $(0-17,18-64$ and above 65$)$ and the (5) age-standardised and sex-standardised rates per 100000 patients with expected AF.

Interrupted time series (ITS) analysis, a quasiexperimental design, was used to evaluate changes in patient outcomes after the implementation of interventions in the Hounslow AF QI initiative. ITS makes use of observational data collected at multiple time points to form a preintervention and postintervention trend, with an interruption' by the intervention between the two trends. ${ }^{18-22}$ This allows the population to act as the control group for itself in this 'natural experiment', reducing selection bias and confounding due to group differences. ${ }^{20-22}$ 


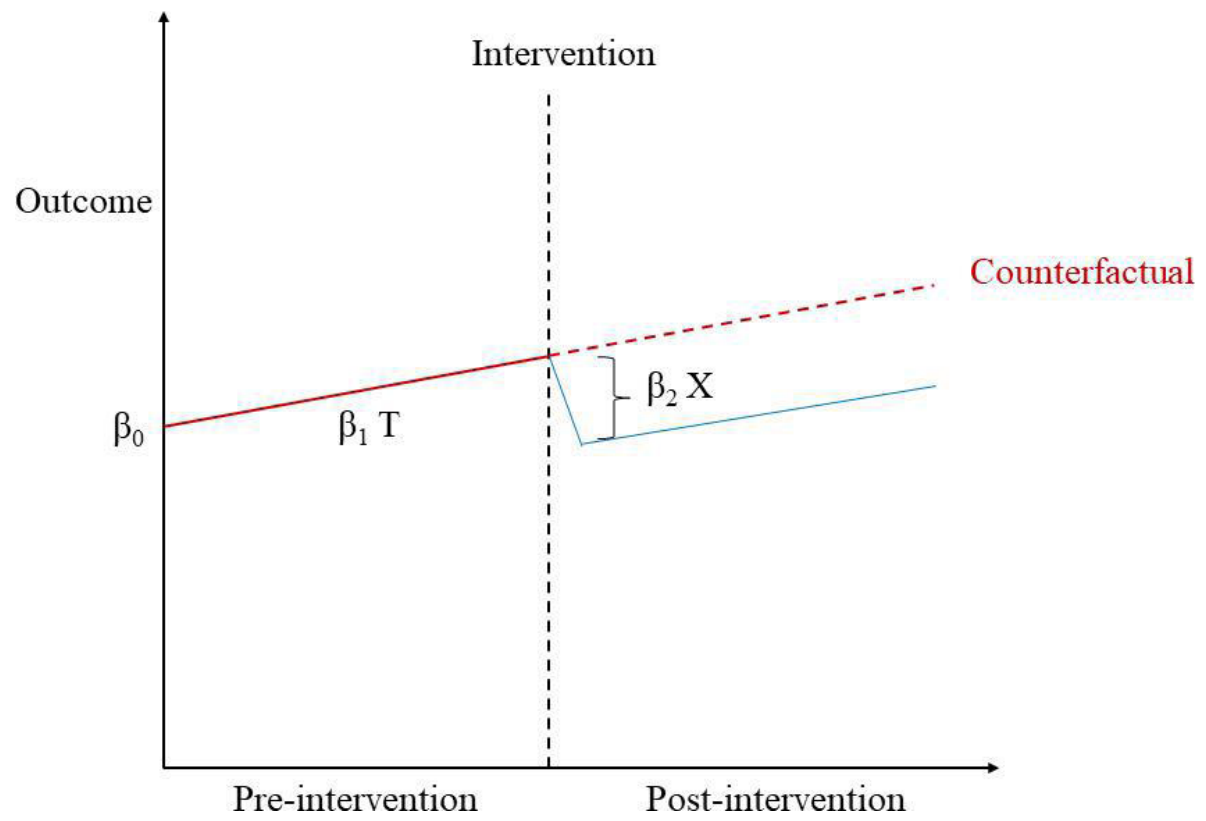

Figure 1 Proposed impact model with a level change for the ITS analysis. Red solid line=preintervention trend; red dashed line=counterfactual; blue line=postintervention trend; $\beta 0=$ intercept representing starting level of outcome variable; $\beta 1=$ slope prior to intervention; $\beta 2=$ change in level after intervention; T=time since start of the study; $X=$ intervention. ITS, interrupted time series.

The chosen preintervention period was from 1 January 2011 to 31 September 2014 and the postintervention period, marked by the start of the implementation of interventions in the Hounslow AF QI initiative, was from 1 October 2014 to 31 August 2018. As the outcomes of interest are counts, Poisson regression models were fitted. The intervention time point was chosen to be closest time point to the intervention start; hence, October 2014 was chosen for the monthly regression model and January 2015 for the 6-monthly regression models. An agestandardised and sex-standardised expected AF population was included as an offset variable to convert the outcomes into rates and adjust for any potential changes in the population over time. Estimates of the expected AF prevalent population in Hounslow were derived based on applying known age and sex distributions of diagnosed $\mathrm{AF}$ in a Swedish study ${ }^{23}$ to the Hounslow population, as has been previously adopted by Public Health England. ${ }^{5}$ Change in the level of the trend was assumed and thus an impact model with a level change was proposed (figure 1). ${ }^{2022}$

This assumption was based on existing evidence that $\mathrm{OAC}$ reduces risk of stroke in patients with an $\mathrm{AF}$ diagnosis. ${ }^{24}$ The equation for the segmented regression model used was:

$$
\mathrm{Y}_{\mathrm{t}}=\beta_{0}+\beta_{1} \mathrm{~T}_{\mathrm{t}}+\beta_{2} \mathrm{X}_{\mathrm{t}}
$$

To ensure robustness of the results, we conducted two sensitivity analyses. First, an additional regression model was created for each of the measures ${ }^{20} 22$ including both the level change and an interaction term $\left(X_{t} T_{t}\right)$ for the slope change. The equation for this segmented regression model used was:

$$
\mathbf{Y}_{\mathbf{t}}=\beta_{0}+\beta_{1} \mathbf{T}_{\mathrm{t}}+\beta_{2} \mathbf{X}_{\mathbf{t}}+\beta_{3} \mathbf{X}_{\mathbf{t}} \mathbf{T}_{\mathbf{t}}
$$

The second sensitivity analysis comprised adjusting for seasonality in each regression model.

Results are presented as incidence rate ratios (IRR) and $95 \%$ CI. Values of $\mathrm{p}<0.05$ were considered to be statistically significant. Models were checked for the goodness of fit and autocorrelation. All the data aggregation and analysis were conducted using STATA 15.1 (Stata, College Station, TX, USA). The Standards for Quality Improvement Reporting Excellence 2.0 guidelines were used as a framework for reporting findings from this QI initiative. ${ }^{25}$

\section{RESULTS}

Descriptive statistics are shown in table 1. Between 2011 and 2018, the expected AF prevalent population increased year on year. The average monthly incidence of admission with stroke as primary diagnosis ranged from 32.3 (4.67) in 2012 to 42.0 (5.6) in 2017; admission with stroke as primary diagnosis and $\mathrm{AF}$ as secondary diagnosis ranged from 9.3 (0.6) in 2013 to 6.4 (0.8) in 2016, admission with bleeding as primary diagnosis and $\mathrm{AF}$ in any position of diagnosis ranged from $2.7(0.9)$ in 2012 to $6.3(0.9)$ in 2017 and admission with bleeding as primary diagnosis and use of $\mathrm{OAC}$ as secondary diagnosis ranged from 1.0 (0.2) in 2012 to 5.3 (0.4) in 2017. Age-standardised and sex-standardised monthly rates per 100000 population followed similar patterns. For the most part, admissions were slightly higher for men than in women for all the measures except for the admission with stroke as primary diagnosis and $\mathrm{AF}$ as secondary diagnosis measure. For all 


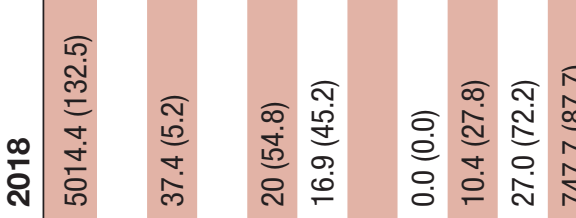
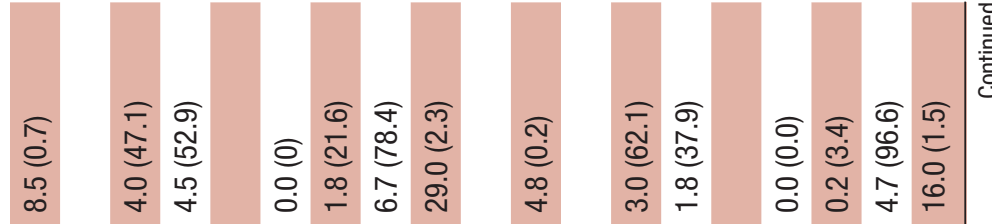

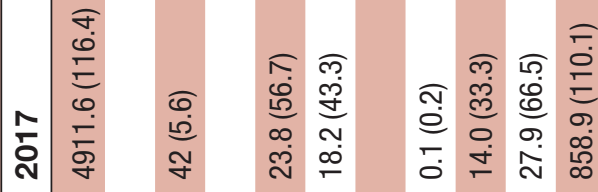

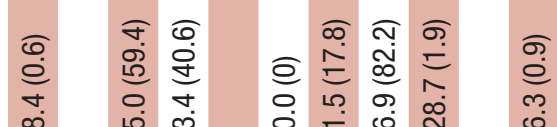

-

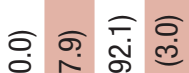

जै ल्ले

ํ.

ต

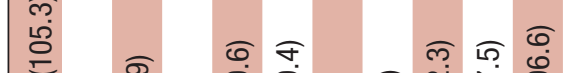

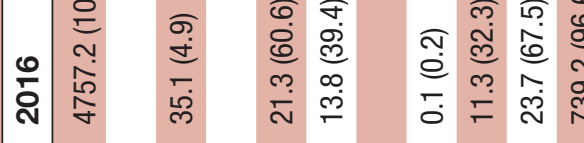

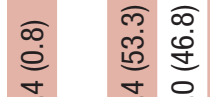

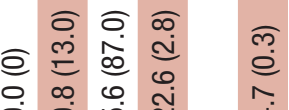

กิ

으

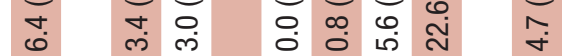

年

등 $\mathrm{m}$ m

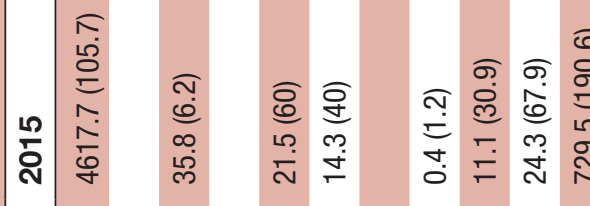

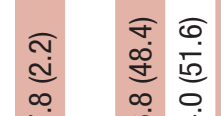

कำ

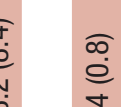

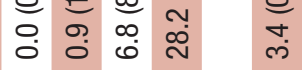

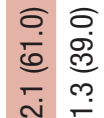

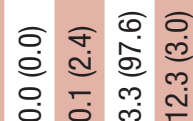

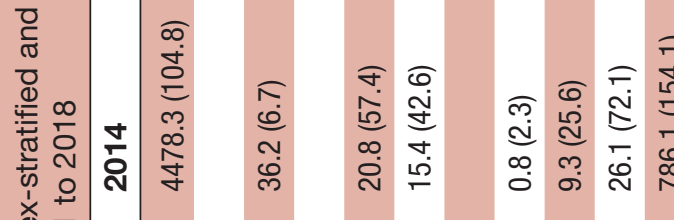

으

ฮํ.

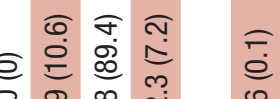

क สุ

ฮิ

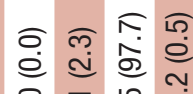

Ni

둥

需

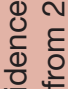

은

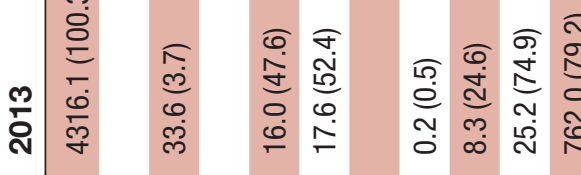

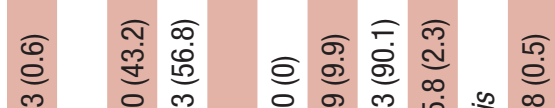

เก็

造望

○ 10 เุ

든

¿

잉

产

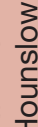

ซ

$\frac{\infty}{6}$

व)

ऽे

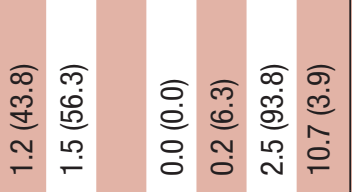

ह.

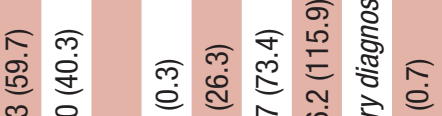

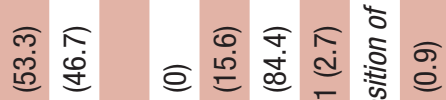

宁

○.

ลิ

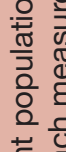

ชิ

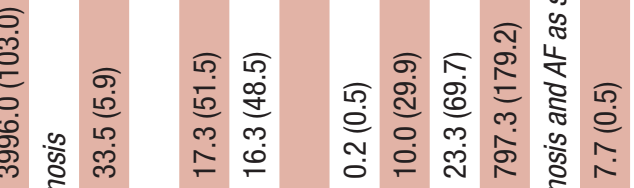

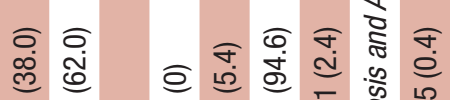

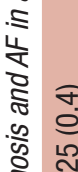

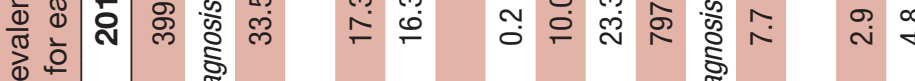

○.

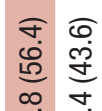

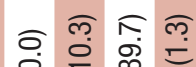

$\stackrel{\infty}{\check{r}}$

0 드

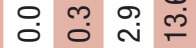

를

崖

के क्षे

ลิ จิ

ลิ

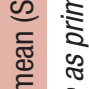

है ฮั

ㄷำ

है ซ

중 중

त莅

ᄃ

을 흔

응 혼

음 喜

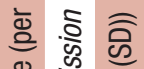

竞 客

들

$\stackrel{0}{\Sigma}$.

$-\frac{\overline{0}}{\frac{0}{0}}$

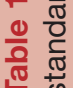

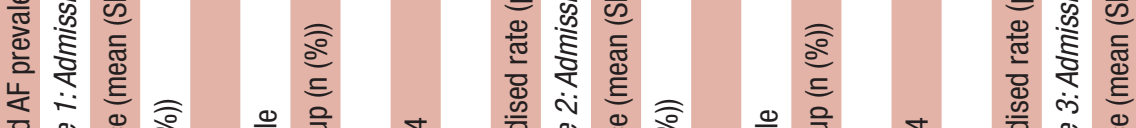

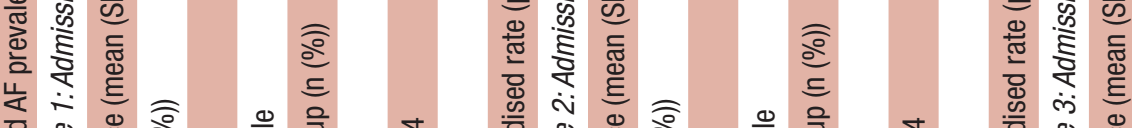

ङ् :

ㅎํㅇ

은 喜

ᄒั ธิ 


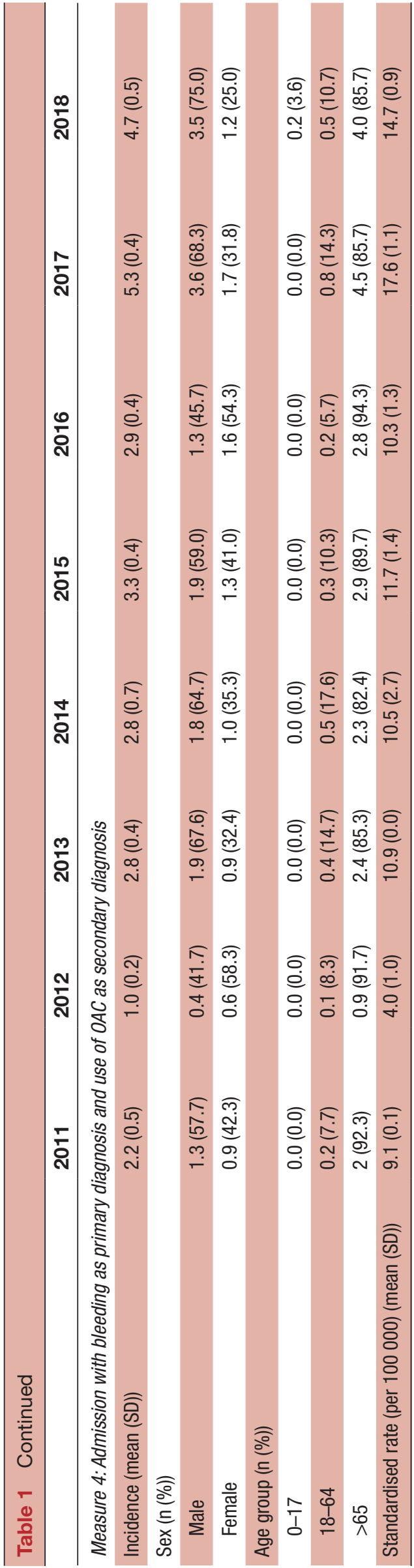

measures, a higher proportion of the admissions were patients aged 65 and above.

\section{Outcome measures}

Stroke admissions

In the postintervention period, there was a $17 \%$ decrease in admission with stroke as primary diagnosis (IRR 0.83; 95\% CI 0.731 to $0.958 ; \mathrm{p}<0.010$ ) (table 2 ). After adjustment for seasonality, the result remained statistically significant (IRR $0.83 ; 95 \%$ CI 0.712 to $0.963 ; \mathrm{p}<0.014$ ) (table 2 and figure 2).

For admission with stroke as primary diagnosis and $\mathrm{AF}$ as secondary diagnosis, there was a $26 \%$ decrease in the postintervention period (IRR 0.74; 95\% CI 0.555 to 0.993 ; $\mathrm{p}<0.045$ ) (table 2). However, after adjusting for seasonality, this decrease did not remain statistically significant (IRR $0.75 ; 95 \%$ CI 0.550 to $1.025 ; \mathrm{p}<0.071$ ) (table 2 and figure 3 ).

\section{Bleeding admissions}

In the postintervention period, there was a non-statistically significant 6\% decrease in admission with bleeding as primary diagnosis and $\mathrm{AF}$ in any position of diagnosis (IRR 0.94; 95\% CI 0.618 to 1.417 ; p<0.755) (table 2). On adjusting for seasonality, a similar non-statistically significant result was observed (IRR $0.93 ; 95 \%$ CI 0.597 to 1.449 ; $\mathrm{p}<0.749$ ) (table 2 and figure 4 ).

There was a non-statistically significant decrease in admission with bleeding as primary diagnosis and use of OAC as secondary diagnosis (IRR $0.93 ; 95 \%$ CI 0.569 to 1.502; $\mathrm{p}<0.751$ ) (table 2). Adjusting for seasonality, indicated similar non-statistically significant $8 \%$ decrease (IRR 0.92; 95\% CI 0.520 to $1.621 ; \mathrm{p}<0.769$ ) (table 2 and figure 5 ).

For all measures, the slope change was small and not statistically significant, with the prevailing upward trend continuing after the step down at the intervention point. The former model was a better fit (lower Akaike Information Criterion) for the data and as a result, the level change model, the parsimonious model, was chosen as the final model.

\section{DISCUSSION}

\section{Principal findings}

The main finding of this study is that a $17 \%$ decrease in hospital stroke admissions was observed in Hounslow following the implementation of interventions in the AF QI initiative. There were no significant changes in rates of admission for bleeding.

\section{Stroke admissions}

Reduction in stroke admissions may have been influenced by interventions deployed in the QI initiative such as the AF clinical template, which included a stroke risk assessment tool to guide appropriate anticoagulation. In addition, education of healthcare professionals (HCP), nurse review of exception-reported and aspirin treated patients, anticoagulation clinics and raising awareness 
Table 2 Estimated effects (IRR) of the intervention variable in the unadjusted and seasonality adjusted ITS level change models

\begin{tabular}{|c|c|c|c|c|c|c|}
\hline & \multicolumn{6}{|c|}{ Intervention (level change) } \\
\hline & \multicolumn{3}{|c|}{ Unadjusted } & \multicolumn{3}{|c|}{ Seasonality adjusted } \\
\hline & IRR & $95 \% \mathrm{Cl}$ & $P$ value & IRR & $95 \% \mathrm{Cl}$ & $P$ value \\
\hline Measure 1 & 0.83 & 0.731 to 0.958 & $<0.010^{\star *}$ & 0.83 & 0.712 to 0.963 & $<0.014^{\star}$ \\
\hline Measure 2 & 0.74 & 0.555 to 0.993 & $<0.045^{\star}$ & 0.75 & 0.550 to 1.025 & $<0.071$ \\
\hline Measure 3 & 0.94 & 0.618 to 1.417 & $<0.755$ & 0.93 & 0.597 to 1.449 & $<0.749$ \\
\hline Measure 4 & 0.93 & 0.569 to 1.502 & $<0.751$ & 0.92 & 0.520 to 1.621 & $<0.769$ \\
\hline
\end{tabular}

Measure 1: admission with stroke as primary diagnosis

Measure 2: admission with stroke as primary diagnosis and AF as secondary diagnosis

Measure 3: admission with bleeding as primary diagnosis and AF in any position of diagnosis.

Measure 4: admission with bleeding as primary diagnosis and use of OAC as secondary diagnosis

${ }^{*} \mathrm{P}<0.05,{ }^{* *} \mathrm{p}<0.01$

$A F$, atrial fibrillation; IRR, incidence rate ratio; ITS, interrupted time series; OAC, oral anticoagulation.

of $\mathrm{AF}$ among patients and in the community, are likely to have enhanced evidence-based clinical practice and contributed to the increased OAC prescription, which in turn mitigates stroke risk.

Although the decrease in seasonally adjusted rate of admission with stroke as primary diagnosis and $\mathrm{AF}$ as secondary diagnosis was not statistically significant, the effect size was the largest compared with the other outcomes, and the $95 \%$ CI only just overlaps 1 . The small numbers of such admissions also impact on this result, and it remains plausible that the intervention had an effect on this measure that was not detectable in this study.

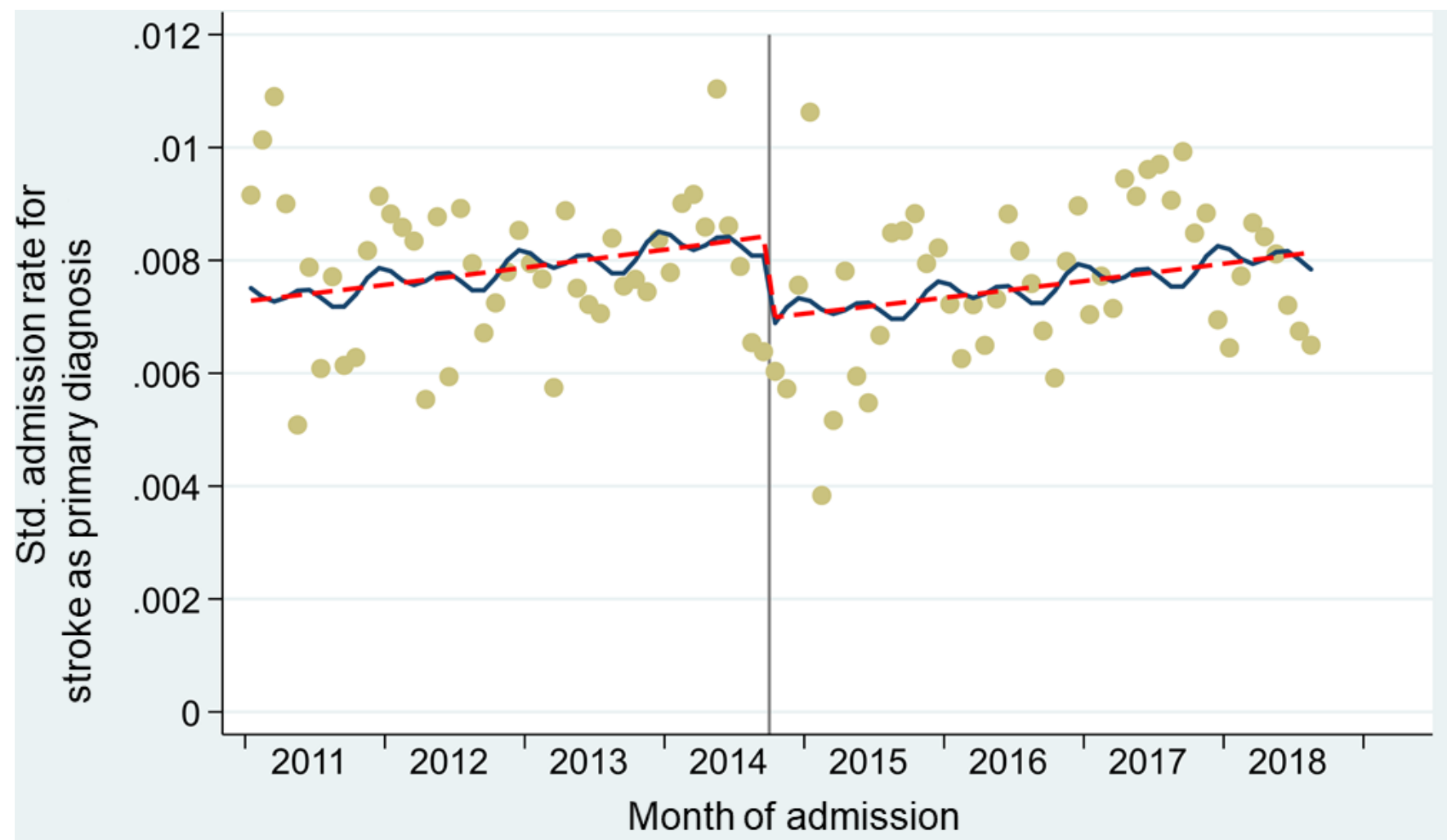

Figure 2 Seasonality adjusted ITS regression showing age-sex-standardised rate of admission with stroke as primary diagnosis in Hounslow CCG from January 2011 to August 2018. Grey vertical line: Intervention time point. Level change in relation to intervention variable: IRR $0.83 ; 95 \% \mathrm{Cl} 0.721$ to $0.963 ; \mathrm{p}<0.014$. AF, atrial fibrillation; $\mathrm{CCG}$, Clinical Commissioning Group; IRR, incidence rate ratio; ITS, interrupted time series. 


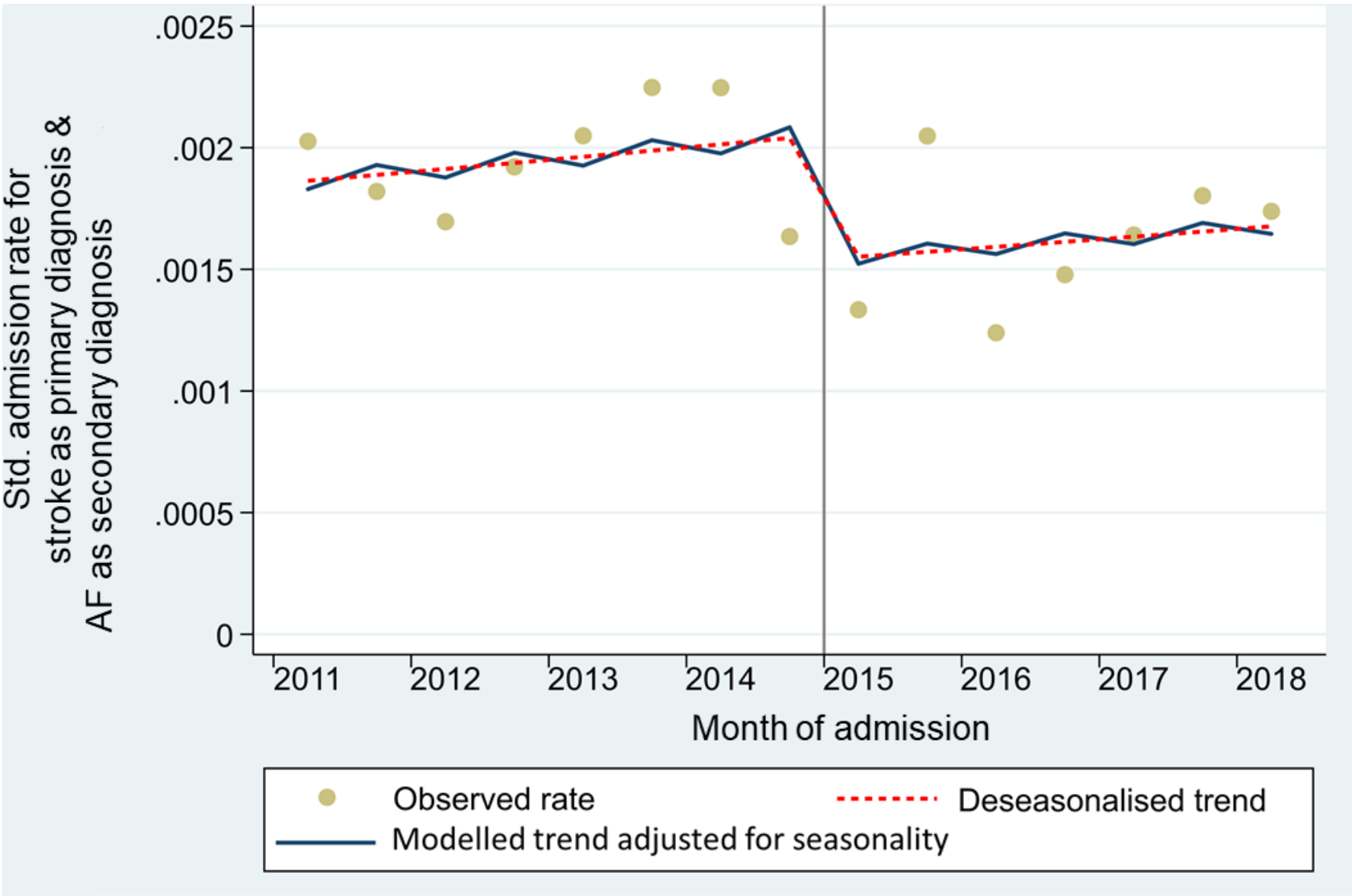

Figure 3 Seasonality adjusted ITS regression showing age-sex-standardised rate of admission with stroke as primary diagnosis and AF as secondary diagnosis in Hounslow CCG from January 2011 to August 2018. Grey vertical line: Intervention time point. Level change in relation to intervention variable: IRR $0.75 ; 95 \% \mathrm{Cl} 0.550$ to $1.025 ; \mathrm{p}<0.071$. AF, atrial fibrillation; CCG, Clinical Commissioning Group; IRR, incidence rate ratio; ITS, interrupted time series.

\section{Bleeding admissions}

This study did not find any evidence that the previously observed increase in prescription of OAC in patients with an AF diagnosis inadvertently increased bleeding admissions, consistent with good anticoagulation practices. Use of bleeding risk assessment tools in the clinical template may have supported GPs' decision making on OAC prescription to patients with newly diagnosed and existing AF with different risk scores and helped identify those at high risk of bleeding who needed to have underlying modifiable factors addressed. It is important to note, however, that with smaller numbers of observed admissions for bleeding than for stroke, this study may not have been powered to detect a change in this secondary outcome.

\section{Comparison with other literature/studies}

An observational study by Cowan et al investigated the temporal trend of OAC uptake and its impact on stroke rates in England and concluded that a 1\% increase of OAC use among patients with AF with high stroke risk is associated with a decline of $0.8 \%$ in weekly hospitalised AF-related strokes. ${ }^{26}$ The increase of OAC uptake across England was attributed to a series of national efforts, for example, guideline updates, QI initiatives, NOAC licensing ${ }^{27}$ and QOF incentivisation. Although not statistically significant, our study corresponds with these findings of a decline in hospitalised AF-related strokes but was focused on the effect of implementation of a local QI initiative and did not adjust for comorbidity. Another study by Maggioni et al followed similar patterns. ${ }^{28}$

A number of studies ${ }^{27} 29$ have reported trends in AF prevalence and OAC uptake over time, mostly in primary care settings, but this study goes further by investigating the AF-related outcomes in secondary care such as stroke and bleeding admissions.

\section{Strengths and limitations}

To our knowledge, this is the first study to evaluate the changes in AF-related outcomes in a local setting using ITS analysis. Although this study cannot be used to infer a causal relationship between the interventions implemented in the Hounslow AF QI initiative and the AF-related outcomes, it adds to the limited existing evidence on stroke and bleeding admissions among patients diagnosed with AF over time. It shows that a QI initiative can potentially contribute towards narrowing the translation gap from evidence to real-world practice, leading 


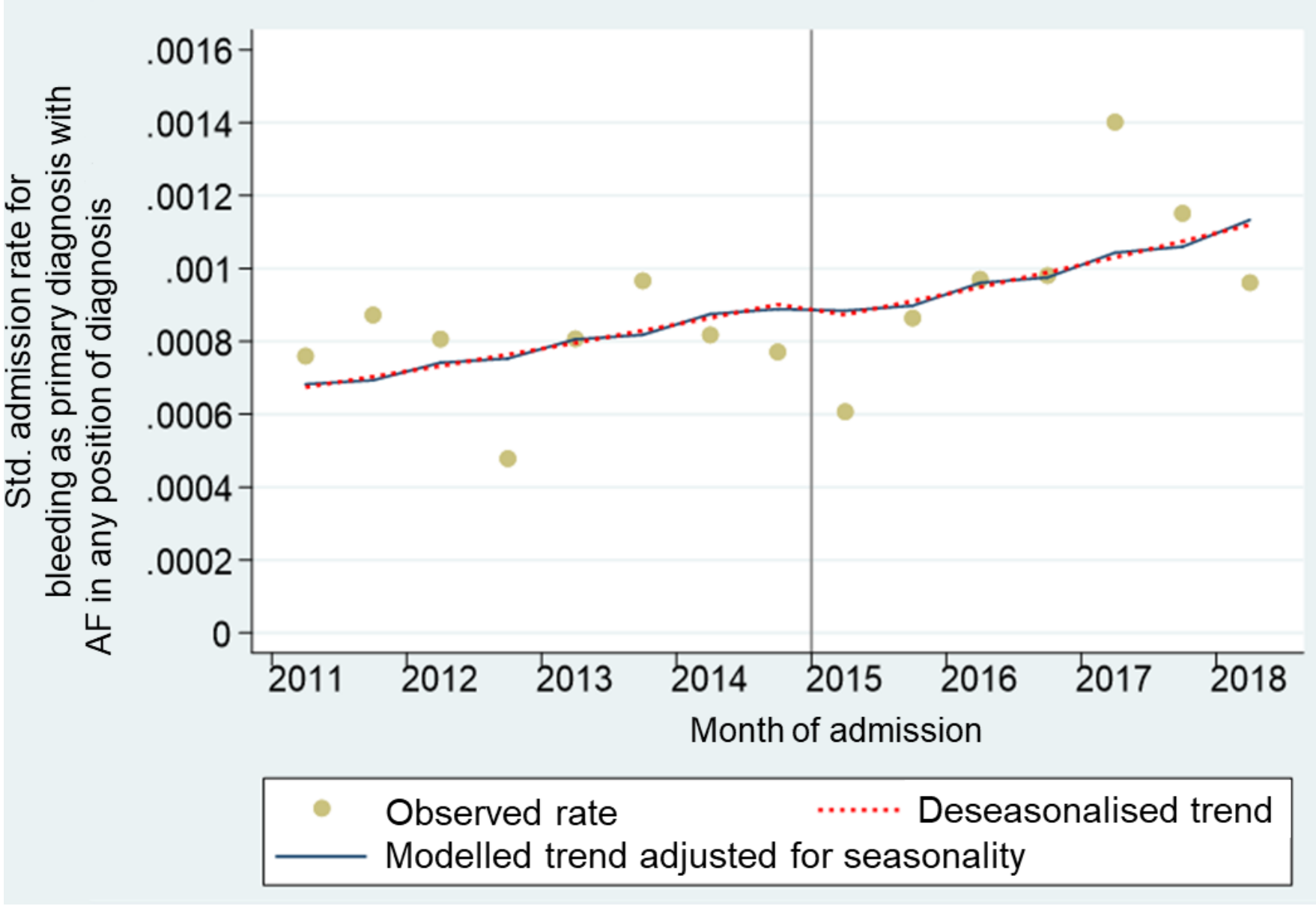

Figure 4 Seasonality adjusted ITS regression showing age-sex-standardised rate of admission with bleeding as primary diagnosis and AF in any position of diagnosis in Hounslow CCG from January 2011 to August 2018. Grey vertical line: Intervention time point. Level change in relation to intervention variable: IRR $0.93 ; 95 \% \mathrm{Cl} 0.597$ to $1.449 ; \mathrm{p}<0.749$. AF, atrial fibrillation; CCG, Clinical Commissioning Group; IRR, incidence rate ratio; ITS, interrupted time series.

to a change in AF-related outcomes, particularly stroke admissions. However, without a control group in this study, it is also possible that the decrease in the rate of stroke admissions was attributable to other secular trends such as the update of NICE guidelines on AF diagnosis and management in June 2014, which recommended OAC prescription for stroke prevention and called for decreased use of antiplatelet drugs. ${ }^{31}$ This study used routine data with standardised ICD-10 coding from the HES database, which helped to maintain objectivity and reduced selection bias. ITS regression is among the more robust non-experimental methods for evaluating change over time, and the model was subjected to a series of model-checking techniques to enhance the robustness of the analysis.

Several limitations exist in this study. First, the use of aggregated HES data without linkage to primary care data meant that possible confounders could not be accounted for and outcomes could not be assessed on an individual patient level, for instance, assessing differences in outcomes for patients diagnosed with AF who had received OAC versus those that had not. HES data do not include people who are treated in the community or died before admissions, who may have had a stroke. Monthly data on the Hounslow AF prevalent population stratified by age and sex were unavailable for standardisation from Quality and Outcomes Framework data and had to be modelled based on data from a Swedish study. ${ }^{23}$ The demographic composition of the reference population in Sweden is likely to have a higher proportion of Caucasians than the more culturally diverse population in Hounslow $^{32}$ and as Caucasians are known to have a higher prevalence of $\mathrm{AF}^{1}$, the modelled expected $\mathrm{AF}$ prevalent population may have been overestimated. Demographic characteristics and practice variations in Hounslow limit the generalisability of the study findings. Additionally, in this study, we did not know when patients were diagnosed with AF and there is no clearly defined lag period for stroke occurrence; hence, a longer follow-up period may have provided a more detailed evaluation. This may be important in cases where we were able to show a trend but no demonstrate statistical significance.

\section{Implications for future research}

Further research could compare AF-related outcomes observed in this study with other regions with similar 


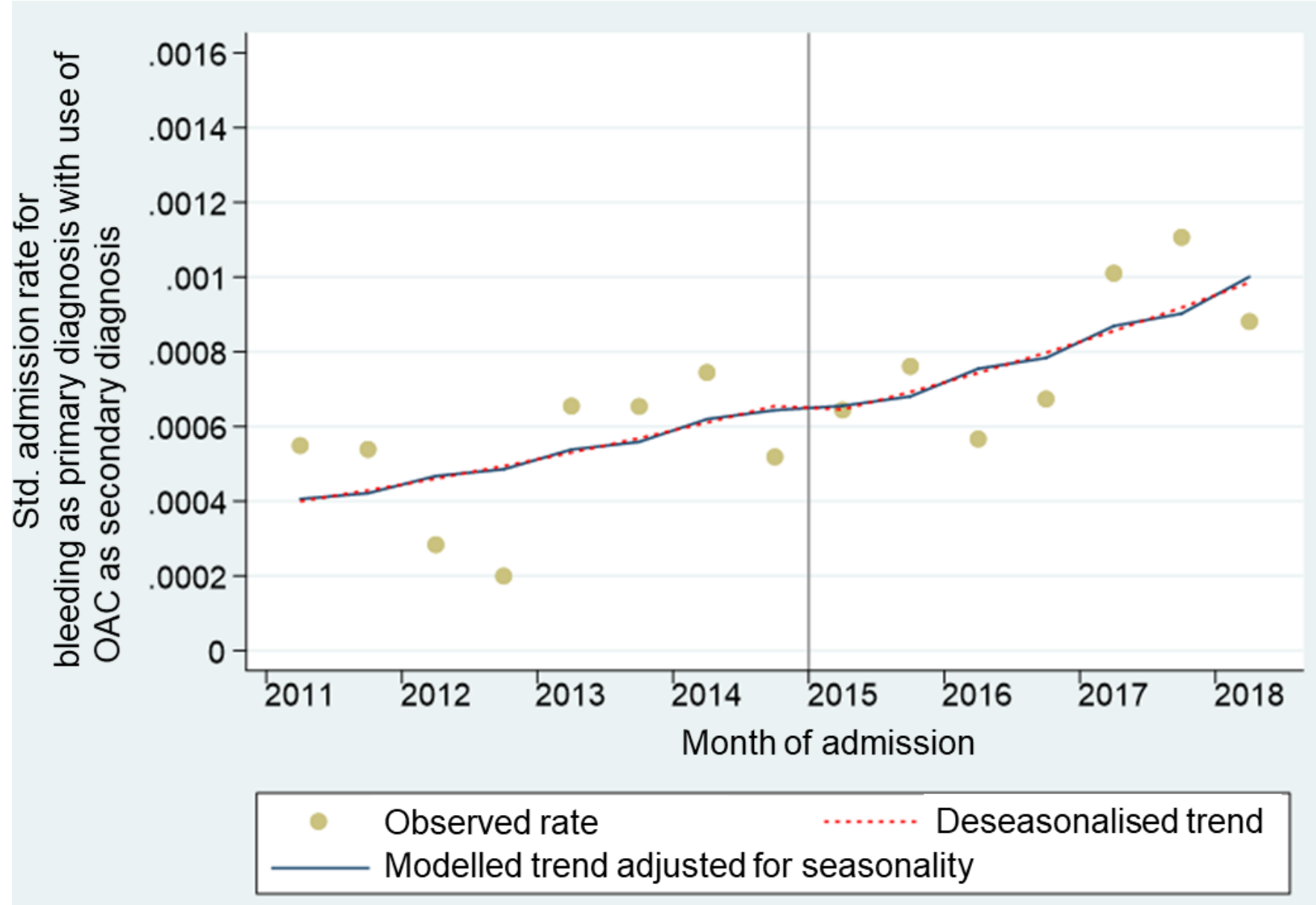

Figure 5 Seasonality adjusted ITS regression showing age-sex-standardised rate of admission with bleeding as primary diagnosis and use of OAC as secondary diagnosis in Hounslow CCG from January 2011 to August 2018. Grey vertical line: intervention time point. Level change in relation to intervention variable: IRR $0.92 ; 95 \% \mathrm{Cl} 0.520$ to $1.621 ; \mathrm{p}<0.769$. CCG, Clinical Commissioning Group; IRR, incidence rate ratio; ITS, interrupted time series; OAC, oral anticoagulation.

demographics and that are yet to embark on initiatives aimed at improving AF care. This would allow the other healthcare areas to serve as control groups for more robust statistical analysis. However, with heightened awareness among HCPs and the pressure to tackle this issue, even at a national level, there is potential for further comparative work to yield null results due to changed clinical practices. ${ }^{33}$ Furthermore, a cohort study which follows the long-term AF-related outcomes of individual patients with $\mathrm{AF}$ would help better understanding of the impact of the QI interventions at the patient level. This could potentially be done by linking patient's primary care and secondary care data. Larger studies could better inform an understanding of the rarer outcomes of this study, including admission for bleeding.

\section{CONCLUSION}

This study reveals that the AF QI initiative in Hounslow was associated with a significant decline in the rate of admission with stroke as primary diagnosis without any significant increases in bleeding admissions. Although not statistically significant, a larger decrease was also observed in admission with stroke as primary diagnosis and AF as secondary diagnosis, the more compelling metric. This study cannot rule out the effect of other factors such as national interventions and wider secular trends but does offer insights into changes in local admission patterns subsequent to this QI initiative. In regions where undiagnosed or poorly managed $\mathrm{AF}$ is evident, similar QI interventions may prove beneficial in reducing the burden of stroke on people living with $\mathrm{AF}$ and on the healthcare system.

\section{Author affiliations}

${ }^{1}$ Department of Primary Care and Public Health, Imperial College London, London, UK

${ }^{2}$ Cardiology, West Middlesex University Hospital, London, UK

${ }^{3}$ Chelsea and Westminster Healthcare NHS Trust, London, UK

${ }^{4}$ Imperial College Health Partners, London, UK

${ }^{5}$ Cardiology Department, Guy's and Saint Thomas' NHS Foundation Trust, London, UK

${ }^{6}$ King's College London, London, UK

${ }^{7}$ North West London Clinical Commissioning Group, London, UK

${ }^{8}$ Upbeat Heart Prevention and Support Group, London, UK

${ }^{9}$ Chiswick Health Practice, London, UK

${ }^{10}$ Harvey Walsh, Cheshire, UK

${ }^{11}$ National Heart \& Lung Institute, Imperial College London, London, UK

Twitter Sadia Khan @sadiahasnain 
Contributors SK devised the study. KYW, YA and TW designed the statistical analyses. JW extracted the raw data directly from NHS Digital. AO and SS validated and provided the data. KYW performed the statistical analyses and wrote the article. All authors revised the article for important intellectual content.

Funding This research was funded by the National Institute for Health Research Collaboration for Leadership in Applied Health Research and Care Northwest London (NIHR CLAHRC NWL), now recommissioned as NIHR Applied Research Collaboration Northwest London. This study was supported in part by a Medical and Education Goods and Services (MEGS) grant from Pfizer and Hounslow CCG provided technology (ie, KardiaMobile (AliveCor) and mobile devices).

Disclaimer The views expressed in this publication are those of the author(s) and not necessarily those of the NIHR or the Department of Health and Social Care.

Competing interests MRC received grants and personal fees from Bayer, personal fees from Pfizer BMS Alliance, outside the submitted work. SK reports grants from Pfizer, during the conduct of the study.

Patient consent for publication Not required.

Ethics approval According to policy on activities that constitute research at West Middlesex University Hospital NHS Trust, this work met criteria for operational improvement activities and is exempt from ethics review. Ethical approval was not required for this work as it was part of a service evaluation and improvement activity and not human subjects research. An ethics waiver was granted by West Middlesex University Hospital NHS Trust research executive.

Provenance and peer review Not commissioned; externally peer reviewed.

Data availability statement All data relevant to the study are included in the article or uploaded as supplementary information.

Open access This is an open access article distributed in accordance with the Creative Commons Attribution Non Commercial (CC BY-NC 4.0) license, which permits others to distribute, remix, adapt, build upon this work non-commercially, and license their derivative works on different terms, provided the original work is properly cited, appropriate credit is given, any changes made indicated, and the use is non-commercial. See: http://creativecommons.org/licenses/by-nc/4.0/.

Correction notice Since the publication of this article, the authors have noticed that the figures were displayed in the wrong order and therefore mismatched with their captions. This has now been corrected.

ORCID iDs

Bethan Davies http://orcid.org/0000-0002-0528-022X

Yewande Adeleke http://orcid.org/0000-0002-4357-9855

Sadia Khan http://orcid.org/0000-0003-0154-1776

\section{REFERENCES}

1 Rahman F, Kwan GF, Benjamin EJ. Global epidemiology of atrial fibrillation. Nat Rev Cardiol 2016;13:501.

2 Wolf PA, Abbott RD, Kannel WB. Atrial fibrillation as an independent risk factor for stroke: the Framingham study. Stroke 1991;22:983-8.

3 Department of Health[DH] Cardiovascular Disease Team. Cardiovascular disease outcomes strategy: improving outcomes for people with or at risk of cardiovascular disease. Available: https:// www.gov.uk/government/publications/improving-cardiovasculardisease-outcomes-strategy [Accessed 30 Oct 2019].

4 NHS Quality and Outcomes Framework[QOF]. QOF database NHS HOUNSLOW CCG: atrial fibrillation. Available: https://www. gpcontract.co.uk/browse/07Y/Atrial\%20Fibrillation/14 [Accessed 10 Jul 2019].

5 Public Health England[PHE]. Atrial fibrillation prevalence estimates for local populations. Available: https://www.gov.uk/government/ publications/atrial-fibrillation-prevalence-estimates-for-localpopulations [Accessed 20 May 2019].

6 London Borough of Hounslow. The Hounslow story 2017 joint strategic needs assessment.. Available: https://www.hounslow. gov.uk/download/downloads/id/1042/the_hounslow_story_-_jsna_ summary document pdf [Accessed $10 \mathrm{Jul}$ 2019].

7 Stroke Association. AF: how can we do better? NHS HOUNSLOW CCG. Available: https://www.stroke.org.uk/sites/default/files/07y.pdf [Accessed $10 \mathrm{Jul}$ 2019].

8 Welton NJ, McAleenan A, Thom $\mathrm{HH}$, et al. Screening strategies for atrial fibrillation: a systematic review and cost-effectiveness analysis. Health Technol Assess 2017;21:1-236.
9 Freedman B, Camm J, Calkins H, et al. Screening for atrial fibrillation: a report of the AF-SCREEN international collaboration. Circulation 2017;135:1851-67.

10 Taggar JS, Coleman T, Lewis S, et al. Accuracy of methods for detecting an irregular pulse and suspected atrial fibrillation: a systematic review and meta-analysis. Eur J Prev Cardiol 2016;23:1330-8.

11 Kirchhof P, Benussi S, Kotecha D, et al. 2016 ESC guidelines for the management of atrial fibrillation developed in collaboration with EACTS. Eur Heart J 2016;37:2893-962.

12 Hart RG, Pearce LA, Aguilar MI. Meta-analysis: antithrombotic therapy to prevent stroke in patients who have nonvalvular atrial fibrillation. Ann Intern Med 2007;146:857-67.

13 Jakobsen M, Kolodziejczyk C, Klausen Fredslund E, et al. Costs of major intracranial, gastrointestinal and other bleeding events in patients with atrial fibrillation - a nationwide cohort study. BMC Health Serv Res 2017;17:398.

14 Reed JE, Howe C, Doyle C, et al. Simple rules for evidence translation in complex systems: a qualitative study. BMC Med 2018;16:92.

15 Adeleke Y, Matthew D, Porter B, et al. Improving the quality of care for patients with or at risk of atrial fibrillation: an improvement initiative in UK general practices. Open Heart 2019;6:e001086.

16 Hospital Episode Statistics [HES]. Available: https://digital.nhs. uk/data-and-information/data-tools-and-services/data-services/ hospital-episode-statistics [Accessed 10 Jul 2019].

17 World Health Organization[WHO]. International classification of diseases, 10th revision (ICD-10). Available: https://www.who.int/ classifications/icd/icdonlineversions/en/ [Accessed 1 Aug 2019].

18 Ramsay CR, Matowe L, Grilli R, et al. Interrupted time series designs in health technology assessment: lessons from two systematic reviews of behavior change strategies. Int J Technol Assess Health Care 2003;19:613-23.

19 Kontopantelis E, Doran T, Springate DA, et al. Regression based quasi-experimental approach when randomisation is not an option: interrupted time series analysis. BMJ 2015;350:h2750.

20 Bernal JL, Cummins S, Gasparrini A. Interrupted time series regression for the evaluation of public health interventions: a tutorial. Int J Epidemiol 2017;46:348-55.

21 Lopez Bernal J, Soumerai S, Gasparrini A. A methodological framework for model selection in interrupted time series studies. J Clin Epidemiol 2018;103:82-91.

22 Linden A. Conducting interrupted time-series analysis for single- and Multiple-group comparisons. Stata J 2015;15:480-500.

23 Norberg J, Bäckström S, Jansson J-H, et al. Estimating the prevalence of atrial fibrillation in a general population using validated electronic health data. Clin Epidemiol 2013;5:475-81.

24 Lip GYH, Lane DA. Stroke prevention in atrial fibrillation: a systematic review. JAMA 2015;313:1950-62.

25 Ogrinc G, Davies L, Goodman D, et al. Squire 2.0 (standards for quality improvement reporting excellence): revised publication guidelines from a detailed consensus process. BMJ Qual Saf 2016;25:986-92.

26 Cowan JC, Wu J, Hall M, et al. A 10 year study of hospitalized atria fibrillation-related stroke in England and its association with uptake of oral anticoagulation. Eur Heart J 2018;39:2975-83.

27 Loo SY, Dell'Aniello S, Huiart L, et al. Trends in the prescription of novel oral anticoagulants in UK primary care. $\mathrm{Br} \mathrm{J}$ Clin Pharmacol 2017;83:2096-106.

28 Maggioni AP, Dondi L, Andreotti F, et al. Four-year trends in oral anticoagulant use and declining rates of ischemic stroke among 194,030 atrial fibrillation patients drawn from a sample of 12 million people. Am Heart J 2020;220:12-19.

29 Apenteng PN, Gao H, Hobbs FR, et al. Temporal trends in antithrombotic treatment of real-world UK patients with newly diagnosed atrial fibrillation: findings from the GARFIELD-AF registry. BMJ Open 2018;8:e018905.

30 Adderley NJ, Ryan R, Nirantharakumar K, et al. Prevalence and treatment of atrial fibrillation in UK general practice from 2000 to 2016. Heart 2019;105:27-33.

31 The National Institute for Health and Care Excellence[NICE]. Atrial fibrillation: management (CG180). Available: https://www.nice.org.uk/ guidance/cg180 [Accessed 10 Jul 2019]

32 NHS Hounslow Clinical Commissioning Group [CCG]. Annual report and accounts 2018/19. Available: https://www.hounslowccg.nhs. uk/media/131658/Hounslow-CCG-Annual-Report-2018-19.pdf [Accessed 19 Jan 2019].

33 Chen Y-F, Hemming K, Stevens AJ, et al. Secular trends and evaluation of complex interventions: the rising tide phenomenon. BMJ Qual Saf 2016;25:303-10. 


\section{Correction: Hospital admissions for stroke and bleeding in Hounslow following a quality improvement initiative}

Wong KY, Davies B, Adeleke Y, et al. Hospital admissions for stroke and bleeding in Hounslow following a quality improvement initiative. Open Heart 2021;8:e01558.

Since the publication of this article, the authors have noticed that the figures were displayed in the wrong order and therefore mismatched with their captions. This has now been corrected. The correct figures and their captions are shown below (figures 1-5).

Figure 1 Proposed impact model with a level change for the ITS analysis. Red solid line $=$ preintervention trend; red dashed line $=$ counterfactual; blue line $=$ postintervention trend; $\beta 0=$ intercept representing starting level of outcome variable; $\beta 1=$ slope prior to intervention; $\beta 2=$ change in level after intervention; $T=$ time since start of the study; $\mathrm{X}=$ intervention. ITS, interrupted time series.

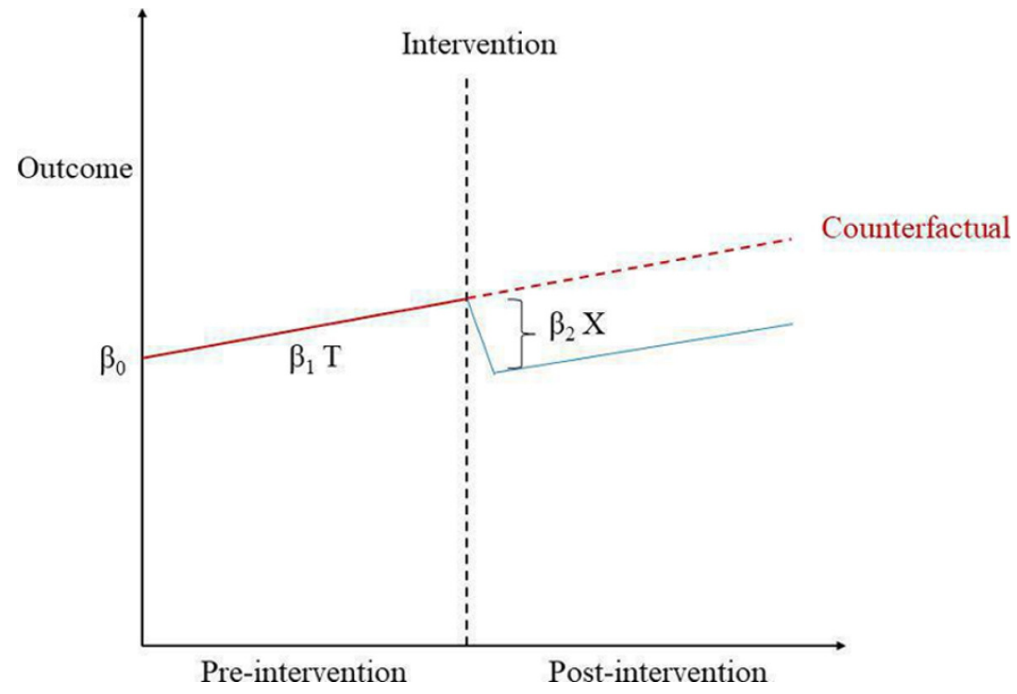

Figure 2 Seasonality adjusted ITS regression showing age-sex-standardised rate of admission with stroke as primary diagnosis in Hounslow CCG from January 2011 to August 2018. Grey vertical line: Intervention time point. Level change in relation to intervention variable: IRR 0.83; 95\% CI 0.721 to 0.963 ; $\mathrm{p}<0.014$. AF, atrial fibrillation; CCG, Clinical Commissioning Group; IRR, incidence rate ratio; ITS, interrupted time series.

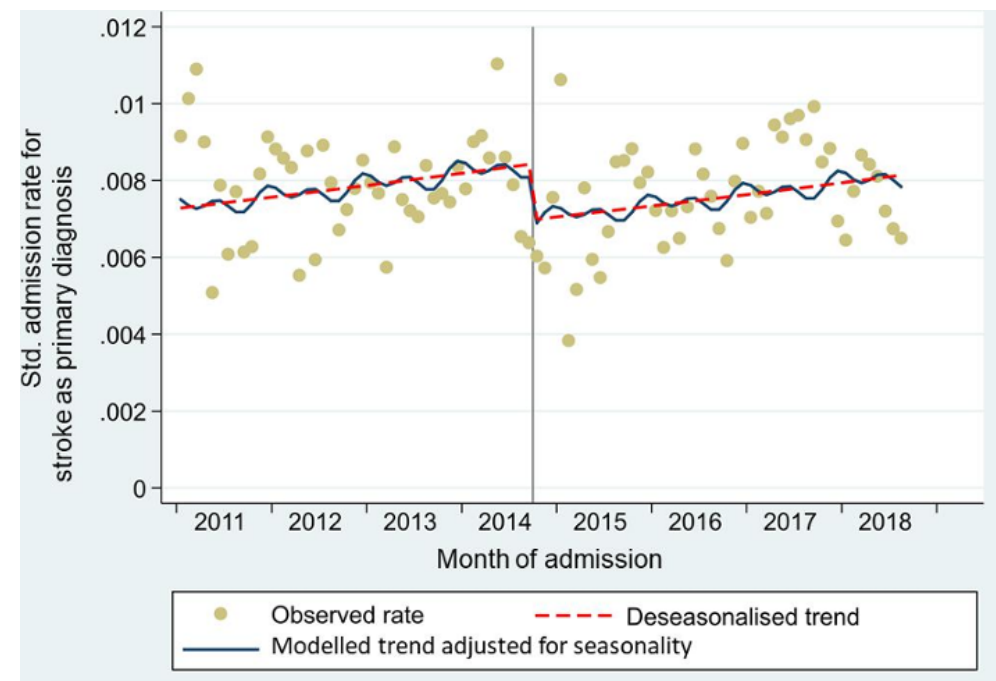


Figure 3 Seasonality adjusted ITS regression showing age-sex-standardised rate of admission with stroke as primary diagnosis and AF as secondary diagnosis in Hounslow CCG from January 2011 to August 2018. Grey vertical line: Intervention time point. Level change in relation to intervention variable: IRR 0.75 ; $95 \%$ CI 0.550 to 1.025 ; $\mathrm{p}<0.071$. AF, atrial fibrillation; CCG, Clinical Commissioning Group; IRR, incidence rate ratio; ITS, interrupted time series.

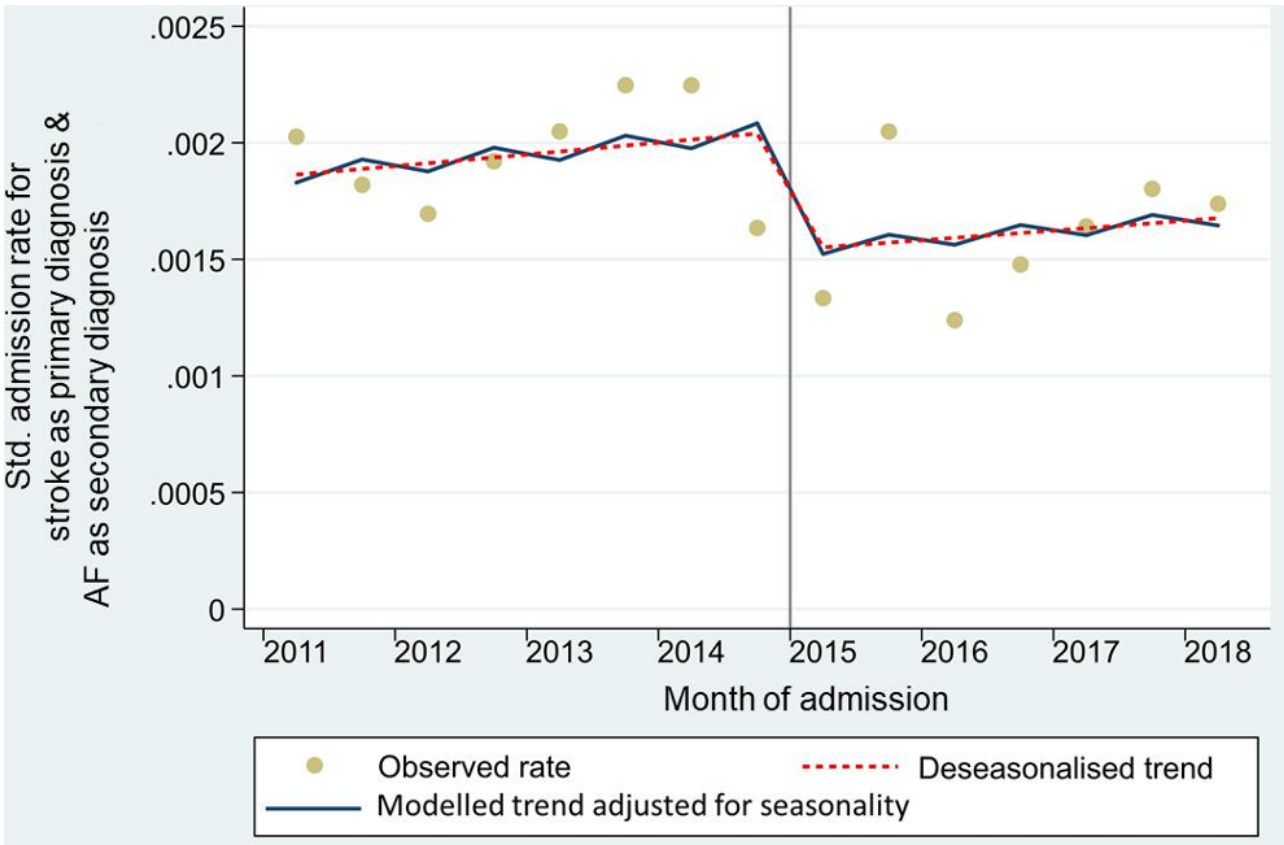

Figure 4 Seasonality adjusted ITS regression showing age-sex-standardised rate of admission with bleeding as primary diagnosis and $\mathrm{AF}$ in any position of diagnosis in Hounslow CCG from January 2011 to August 2018. Grey vertical line: Intervention time point. Level change in relation to intervention variable: IRR $0.93 ; 95 \%$ CI 0.597 to $1.449 ; \mathrm{p}<0.749$. AF, atrial fibrillation; CCG, Clinical Commissioning Group; IRR, incidence rate ratio; ITS, interrupted time series.

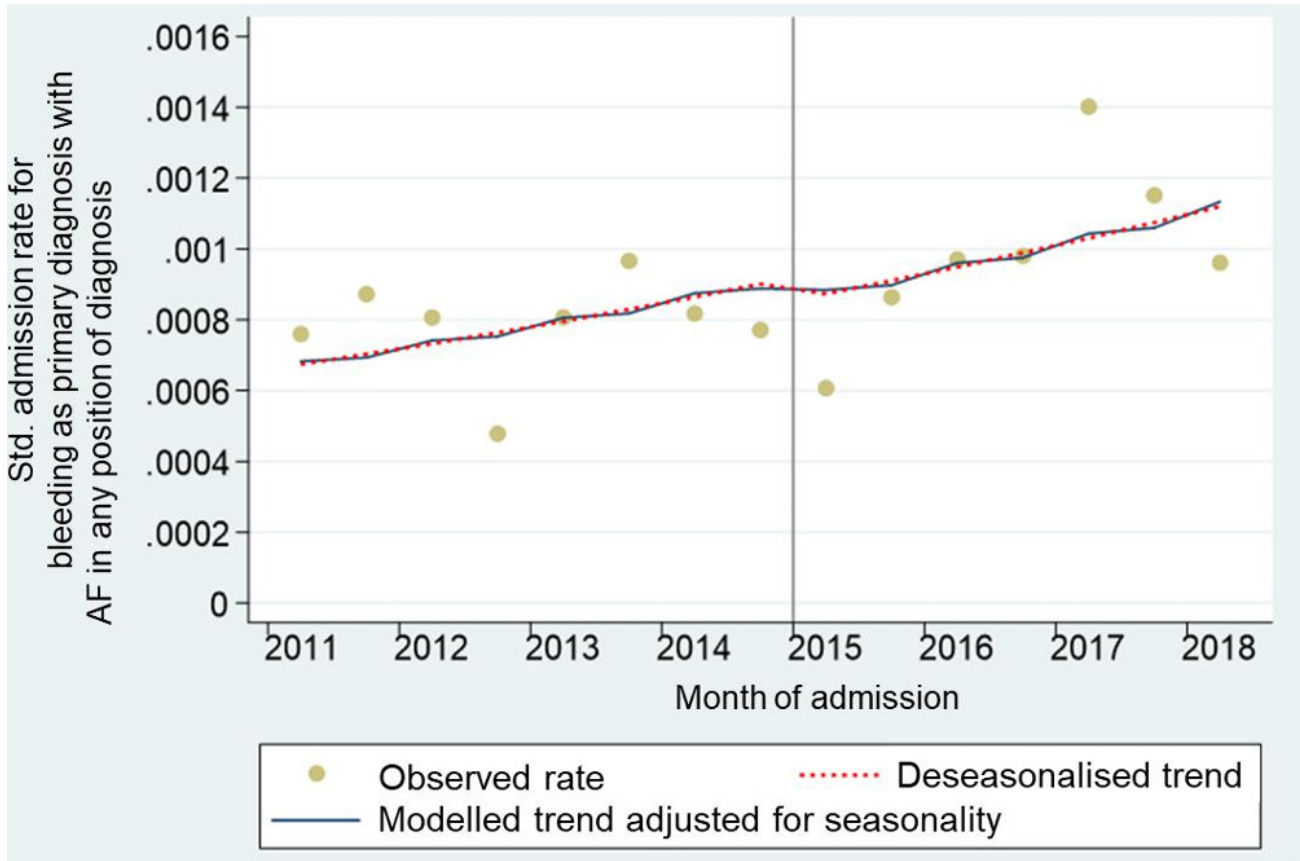


Figure 5 Seasonality adjusted ITS regression showing age-sex-standardised rate of admission with bleeding as primary diagnosis and use of OAC as secondary diagnosis in Hounslow CCG from January 2011 to August 2018. Grey vertical line: intervention time point. Level change in relation to intervention variable: IRR 0.92; 95\% CI 0.520 to 1.621; $\mathrm{p}<0.769$. CCG, Clinical Commissioning Group; IRR, incidence rate ratio; ITS, interrupted time series; OAC, oral anticoagulation.

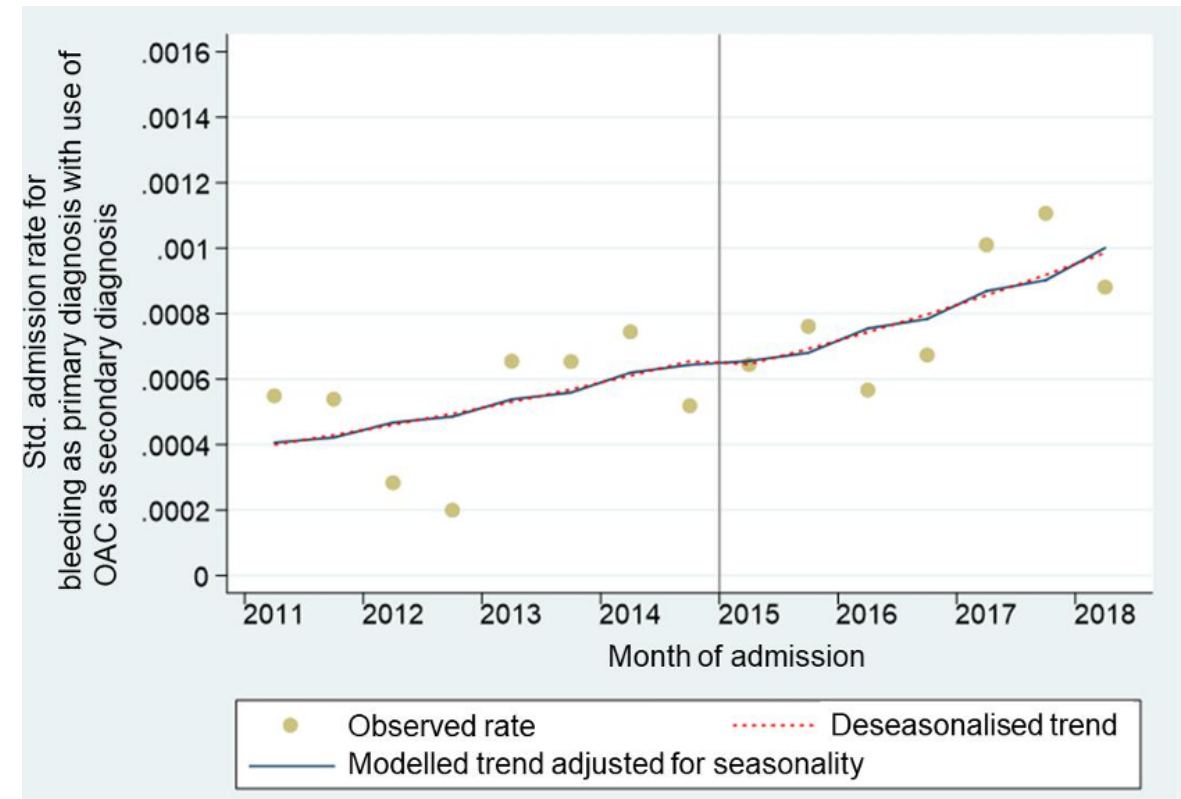

Open access This is an open access article distributed in accordance with the Creative Commons Attribution Non Commercial (CC BY-NC 4.0) license, which permits others to distribute, remix, adapt, build upon this work non-commercially, and license their derivative works on different terms, provided the original work is properly cited, appropriate credit is given, any changes made indicated, and the use is non-commercial. See: http://creativecommons.org/licenses/by-nc/4.0/.

C Author(s) (or their employer(s)) 2021. Re-use permitted under CC BY-NC. No commercial re-use. See rights and permissions. Published by BMJ.

Open Heart 2021;8:e001558corr1. doi:10.1136/openhrt-2020-001558corr1

D) Check for updates 